\title{
Condición juvenil en tiempos de guerra: relatos desde la ruralidad colombiana
}

\author{
Rayén Amanda Rovira-Rubio, Ph. D. ${ }^{a}$ \\ Centro de Estudios Avanzados en Niñez y \\ Juventud Cinde-Universidad de Manizales, \\ Colombia
}

\author{
Patricia Elizabeth León-Saavedra, Ph. D. ${ }^{b}$ \\ Universidad de los Llanos, Colombia
}

rrovira@unal.edu.co

\section{Resumen (analítico)}

El artículo analiza las implicaciones de la guerra en la configuración del ser joven rural en Colombia en La Merced (Caldas) y Vista Hermosa (Meta). Es una investigación cualitativa con enfoque narrativo, que indaga en las experiencias de tres sobrevivientes de la violencia entre los años 1995 y 2005, por medio de marcadores de juventud. De los resultados se desprende que la guerra trazó cursos de vida a los jóvenes rurales, como ser cultivadores de hoja de coca e integrantes de grupos armados, marcándose transiciones en las que se restringieron las capacidades para agenciar posibilidades de futuro fuera de los marcos de la guerra, pero también cursos de vida en resistencia vinculados a la acción colectiva con otros jóvenes.

\section{Palabras clave}

Joven rural, guerra, violencia, memoria, método cualitativo.

\section{Thesauro}

Tesauro de Ciencias Sociales de la Unesco.

\section{Para citar este artículo}

Rovira-Rubio, R. A., \& León-Saavedra, P. E. (2021). Condición Juvenil en tiempos de guerra: relatos desde la ruralidad colombiana (1995-2005). Revista Latinoamericana de Ciencias Sociales, Niñez y Juventud, 19(2), 1-24. https://dx.doi.org/10.11600/ rlcsnj.19.2.4433

\section{Historial}

Recibido: 13.04 .2020

Aceptado: 09.07.2020

Publicado: 21.06.2021

\section{Información artículo}

Este artículo es producto de una indagación conjunta entre dos investigaciones del grupo Jóvenes, culturas y poderes: Desde las memorias: configuración de la juventud en tiempos de guerra en Vista Hermosa, Meta (noviembre de 2018-enero de 2020); y Cartografías de la re-existencia juvenil en el presente colombiano: una indagación para la territorialización de la paz (noviembre del 2017 a abril 2020). Este trabajo conjunto fue desarrollado entre septiembre 2018 y junio 2019. Área: ciencias sociales. Subárea: estudios de juventud. 


\section{Youth condition in times of war: Stories from Colombian rurality (1995-2005)}

\section{Abstract (analytical)}

This article analyzes the implications of war in the configuration of rural youth in Colombia in La Merced, Caldas and Vista Hermosa, Meta. It describes qualitative research that uses a narrative approach to analyze the experiences of three survivors of violence between 1995 and 2005 through the telling of significant events that occurred during their youth. The results show that the war established specific life courses for rural youth, such as growing coca leaf and being a member of armed groups. These transitions demonstrate how their capacity to pursue possible life paths outside the framework of war were restricted, but also highlight life paths involving resistance to the war that were linked to collective action with other young people.

Keywords

Rural youth, war, violence, collective memory, qualitative method.

\section{Condição juvenil em tempos de guerra: relatos da ruralidade colombiana (1995-2005)}

Resumo (analítico)

O artigo analisa as implicações da guerra na configuração da juventude em zonas rurais da Colômbia, em La Merced, Caldas e Vista Hermosa, Meta. É uma pesquisa qualitativa com abordagem narrativa a partir da qual são analisadas as vivências de três sobreviventes de violência entre $1995 \mathrm{e}$ 2005, por meio dos marcadores juvenis. Os resultados mostram que a guerra traçou rumos de vida para a juventude rural, como ser cultivadores de folha de coca e membros de grupos armados, marcando transições em que se restringiam as capacidades de encontrar possibilidades de futuro fora dos marcos da guerra, mas também, cursos de vida em resistência vinculados à ação coletiva com outros jovens.

\section{Palavras-chave}

Juventude rural, guerra, violência, memória, método qualitativo.

\section{Información autoras}

[a] Psicóloga, Universidad de Santiago de Chile. Magíster y Doctorado en Psicología Social, Universidad Autónoma de Barcelona (España). Profesora del Doctorado en Ciencias Sociales, Niñez y Juventud del Centro de Estudios Avanzados en Niñez y Juventud, Universidad de Manizales y el Cinde. (iD) 0000-0003-1644-977X. H5: 3. Correo electrónico: rrovira@unal.edu.co

[b] Enfermera, Magíster en desarrollo educativo y social, Universidad Pedagógica Nacional-Cinde. Doctora en Ciencias Sociales, Niñez y Juventud, Universidad de Manizales-Cinde. Profesora investigadora en el Grupo de Investigación Favisa, Facultad Ciencias de la Salud, Universidad de los Llanos. iD 0000-0002-5252-2092. H5: 2. Correo electrónico: pleon@unillanos.edu.co 


\section{Introducción}

$S_{\text {cia fácil de sobrevivir ni de contar; menos aún cuando la experiencia ha sido la }}$ de niños, niñas o jóvenes que no han decidido ser parte de ella. El presente artículo hace referencia a la configuración de la condición juvenil en tiempos de guerra; particularmente, acerca de las experiencias de aquellos que vivenciaron la guerra en territorios rurales y sufrieron violencias directas (Calderón, 2009; Galtung, 2004), siendo parte de las comunidades desarmadas que intentaron hacer vida en medio del conflicto, de las cuales hoy existen miles de desaparecidos, secuestrados, desplazados y muchos otros afectados (Centro Nacional de Memoria Histórica, [CNMH], 2013). ${ }^{1}$

La guerra en Colombia ha configurado escenarios de muerte y también otros modos de vida (Ospina-Ramírez \& Ospina-Alvarado, 2017) que quedaron grabados en la memoria de los jóvenes. Hoy podemos recorrer algunos de ellos para comprender, por una parte, la manera en que se gesta el presente en los territorios que han estado en guerra; $y$, por otra, cómo se configuró la condición juvenil de quienes hoy son sus sobrevivientes. Estos son elementos fundamentales para la construcción de las memorias sociales de los territorios colombianos (Halbwachs, 2005).

Seguirle la huella al dolor que ha dejado la guerra en Colombia es un camino que ya se ha comenzado a narrar con fuerza desde el Centro Nacional de Memoria Histórica (2013) y desde otras investigaciones nacionales en niñez y juventud (Castellanos-Obregón \& Torres-Silva, 2008). Estas han evidenciado cómo gran parte de los actuales jóvenes han crecido inmersos en una cultura donde las violencias asociadas al conflicto armado se

\footnotetext{
${ }^{1}$ En cifras, como efectos de las violencias directas de la guerra en Colombia (Galtung, 2004), se han notificado de 182803 desaparecidos, 37386 víctimas de secuestro, 8078127 desplazados, 32737 víctimas de violencia sexual y 9037 menores de 18 años vinculados a grupos armados (Gobierno de Colombia, 2019). El desplazamiento forzado fue el hecho victimizante de mayor afectación en los y las jóvenes, al ser vivido con mayor intensidad en las zonas rurales con un $48.3 \%$ (Bedoya et al., 2019); de igual manera, el reclutamiento forzado en estos territorios es otro indicador predominante (Mantilla-Flórez et al., 2018).
} 
han naturalizado y en su banalización resultan incorporadas en el habitus de la sociedad colombiana, mucho más de lo que la población lo percibe (Koessl, 2015). Estas tramas han tejido sufrimiento social y desconfianza en el diario vivir entre los miembros de las comunidades afectadas, como plantea la investigación sobre los efectos de la violencia paramilitar en habitantes de Miraflores (Boyacá) desarrollada por Carvajal y Galvis (2018).

Ser joven se comprende como todo sujeto a quien la sociedad en la cual vive considera como tal (Alba, 1997); por ende, es una categoría asumida comúnmente como una construcción social de sujetos que tienen un papel fundamental en la construcción del futuro de la sociedad (Berger \& Luckmann, 1998; Simmonds \& Hurtado, 2011). De este modo, el joven se define al relacionarse en cada una de las instituciones sociales como la familia, la escuela y también por los grupos de pares y los modos regulativos que generan las políticas públicas (Tobón, 2005), configurándose como una construcción histórica, social y cultural, no existiendo una sola forma de ser joven² (Bourdieu, 1990; Mosqueira, 2010).

Desde las teorías clásicas de la juventud, los y las jóvenes se encuentran en un periodo de latencia, vivenciando un estado de tiempo libre legítimo y legal, aceptado socialmente para el goce y la distracción (Sepúlveda, 2013). Dicho estado se abandonaría al llegar a cumplir ciertos criterios sociales que accionarían como marcadores de la adultez: un hogar, el ingreso a la vida laboral o la finalización de sus estudios (Margulis, 2001; Margulis \& Urresti, 1998).

Las transformaciones sociales de las últimas décadas han alterado la comprensión de la juventud como transición a la adultez, a la vez que los marcadores de la adultez también se han tornado flexibles (Sepúlveda, 2013). Actualmente el ser joven se asocia a nuevos contextos y expresiones de identidad como procesos multidimensionales fragmentados, en cuales es necesario comprender cómo las personas construyen el sentido de sus vidas socialmente, en trayectorias sociales más amplias que son las que le otorgan significado a la experiencia juvenil (Elder, 1985).

En Latinoamérica, la condición juvenil se encuentra cada vez más atravesada por la precariedad, la incertidumbre y el desencanto (Pineda \& Muñoz, 2017; Reguillo, 2010; Reguillo, 2017; Valenzuela, 2015). Las y los jóvenes también son señalados comúnmente en el espacio público-político desde su criminalización, al ser descritos como los violentos,

\footnotetext{
${ }^{2}$ Los contextos culturales en los cuales se desarrolla el periodo juvenil están determinados por relaciones de poder que crean dispositivos de regulación, ordenan las formas de relación orientando la producción, apropiación, circulación y consumo de conocimientos, saberes, prácticas y representaciones sociales (Bourdieu, 199o; Castellanos-Obregón, 2011; Feixa, 1999; Reguillo, 2010).
} 
los delincuentes, los rebeldes (Jelin, 1994; Martín-Barbero, 1998; Rovira-Rubio, 2014). Sumado a ello, existen diferencias marcadas en las experiencias de juventud según clases sociales, donde las mayores dificultades de acceso las tienen los jóvenes de sectores populares y rurales (Muñoz-López \& Alvarado, 2011). Contextos donde continúa existiendo una invisibilidad acerca de la tendencia urbanizante de los estudios de juventud (González-Cangas, 2003), que no da crédito a las complejas realidades que viven los jóvenes en la ruralidad latinoamericana, dando como resultado un escaso desarrollo de la juventud rural como tema de debate, discusión y planteamiento de políticas específicas (Jurado \& Tobasura, 2012; Kessler, 2005).

Particularmente, en Colombia los jóvenes presentan múltiples dificultades (RoviraRubio et al., 2018), referentes a los marcos de la desregulación social que han generado los conflictos armados por el territorio. La ruralidad ha sido el escenario central de la guerra y los jóvenes estigmatizados por las labores vinculadas a los sistemas de producción y comercialización de la marihuana y la coca, así como a roles asociados a la guerra, prácticas a las que se han asociado por búsquedas de opción de trabajo en contextos de extrema precariedad (CNMH, 2018).

Otro elemento a considerar es el hecho de que en la guerra las prácticas sociales de cuidado y bienestar para el desarrollo de niños, niñas y jóvenes se ponen en tensión, generando separación de instituciones desde las cuales los jóvenes desarrollan sus procesos de socialización (la familia y la escuela), alterando los procesos de transición hacia su juventud (Bedoya et al., 2019). Lo anterior genera efectos psicológicos para quienes sobreviven (Andrades \& Benavides, 2012), que dan cuerpo al trauma psicosocial (Martín-Baró, 1990) por las diversas afectaciones de los años de exposición a la violencia. Estas heridas — que se vuelven parte del diario vivir- influyen en las relaciones mediante las cuales esas personas se construyen a sí mismas y a sus mundos de vida (Montero, 2004); 3 ello obstaculiza el reconocimiento del dolor del otro y altera los valores de los pueblos, escindiendo con ello el tejido social y solidario de la comunidad, lo que hace difícil el encuentro. Este es un lugar afectivo que, al buscar reconstruirlo de la mano de las memorias, se convierte en camino doloroso y difícil (Beristain et al., 1993); no obstante, es un camino necesario para reconfigurar la memoria social tanto de los hechos de violencia como de las formas de vida que permitieron la sobrevivencia pese a la guerra.

\footnotetext{
${ }^{3}$ En estos contextos los jóvenes pueden llegar a anular sus recursos cognitivos y emocionales sin poder recuperarlos por sí mismos, quedando sujetados al pasado traumático que se imponen a nivel de conciencia (Puig \& Rubio, 2015).
} 
Los sujetos que nacieron o vivieron su infancia y juventud entre 1996 y 2002 son aquellos que han transitado su vida en los tiempos más explosivos de la guerra (CNMH, 2013), ${ }^{4}$ siendo muy pocos los que han podido compartir abiertamente sus relatos de vida por la prevalencia del miedo y falta de justicia ante las miles de víctimas del conflicto armado. Es por ello que la escucha de estos testimonios aporta especialmente a la comprensión del ser joven en los años más violentos de la guerra y a la identificación de los marcadores de la juventud (Sepúlveda, 2013) que hicieron que los sujetos se hayan identificado como jóvenes rurales y hayan construido, pese a todo, mundos juveniles.

Según los planteamientos de Elder (1985) y Sepúlveda (2013), el curso de vida está determinado por los sentidos que otorgamos a la misma, siempre cambiantes y condicionados por ciertos acontecimientos dados por un hecho concreto en un tiempo sociohistórico específico y en una relación particular con las instituciones. En este sentido, consideraremos que los marcadores de la juventud se encuentran definidos por: 1) la comprensión que los sujetos tienen de sus contextos de vida; 2) las trayectorias sociales posibles en la vida colectiva; y 3 ) las transiciones que identifican aquello que ha marcado sus cursos de vida posibles. En este caso, nos centraremos particularmente en los marcos de guerra que vivieron los jóvenes, determinantes en su condición juvenil.

Con base en lo anterior, el estudio tiene como objetivo comprender cómo se configuró la condición juvenil de jóvenes rurales en dos territorios atravesados por las violencias de guerra, particularmente entre los años 1995 y 2005: La Merced (Departamento de Caldas) y Vista Hermosa (Departamento del Meta).

\section{Método}

Desde el construccionismo social como apuesta epistémica, desde el lenguaje los sujetos se construyen en las relaciones en las que participan de manera histórica, social, política, económica (Gergen \& Gergen, 2011). A partir de ello, esta investigación se encuadra en el método narrativo al revalorizar al sujeto como actor social en su configuración de la realidad social (Pujadas, 20oo). Su alcance es de tipo exploratorio, en tanto que en Colombia no se han desarrollado investigaciones de este tipo en los territorios focalizados.

\footnotetext{
${ }^{4}$ «Se dio una tendencia explosiva entre 1996 y 2002, en la que el conflicto armado alcanzó su nivel más crítico como consecuencia del fortalecimiento militar de las guerrillas, la expansión nacional de los grupos paramilitares, la crisis del Estado, la crisis económica, la reconfiguración del narcotráfico y su reacomodamiento dentro de las coordenadas del conflicto armado» (CNMH, 2013, p. 33).
} 
El estudio surge de una alianza entre dos proyectos de investigación desarrollados en el marco del grupo de investigación Jóvenes, culturas y poderes, 5 como una unión que permitió amplificar los resultados de ambos ejercicios investigativos y profundizar particular en la comprensión de la condición juvenil rural en tiempos de guerra en el país.

El muestreo de la investigación fue de tipo bola de nieve (Atkinson \& Flint, 2001), por lo que los tres colaboradores en la investigación fueron seleccionados de forma intencional bajo los criterios de conveniencia, oportunidad y disponibilidad de los relatos de vida, en los municipios de La Merced (Caldas) y uno de Vista Hermosa (Meta).

A los colaboradores se les informó sobre el estudio y se procedió a la firma de los consentimientos informados y al uso de seudónimos con el fin de preservar la confidencialidad y anonimato en las narrativas. Los tres colaboradores habitan actualmente los territorios y vivieron en ellos entre los años 1995 y 2005:

- Jorge y Carlos vivieron su niñez y parte de su juventud principalmente entre el 2000 y el 2005 en la Merced ${ }^{6}$, zona afectada por el paramilitarismo durante tiempo prolongado, siendo un lugar estratégico a nivel departamental por ser el punto desde donde se dividió la soberanía del paramilitarismo en el territorio caldense (Rodríguez, 2017).

- Hernán, quien siendo niño llega a la vereda El Laurel en Vista Hermosa, viviendo la dureza de la guerra en este territorio del que tuvo que desplazarse en 1999 para volver luego de unos años. Vista Hermosa ${ }^{7}$ es un territorio que se gesta en las disputas de la guerra desde la década de los años cincuenta y que en el periodo

\footnotetext{
${ }^{5}$ Las investigaciones implicadas en una línea de programa dentro del grupo fueron la tesis doctoral Desde las memorias: configuración de la juventud rural en tiempos de guerra en Vista Hermosa, Meta y Cartografías de la re-existencia juvenil en el presente colombiano: una indagación para la territorialización de la paz.

${ }^{6}$ Municipio del occidente del departamento de Caldas, con 6300 habitantes aproximadamente. Según el registro único de víctimas, al 1 de septiembre del 2019, se encuentran 91697 personas víctimas en dicho departamento; los principales hechos victimizantes son: el desplazamiento forzado, el acto terrorista y las amenazas (Gobierno de Colombia, 2019).

${ }^{7}$ Municipio rural, con una población aproximada de 24154 habitantes. Territorio estratégico para la comercialización de cultivos ilícitos, marcado por múltiples violencias ocasionadas por los enfrentamientos entre las Fuerzas Armadas Revolucionarias de Colombia (Farc-EP), el ejército y los paramilitares. Allí se han identificado 10868 víctimas del conflicto discriminadas así: 10233 desplazamientos, 329 homicidios y 306 víctimas de desaparición forzada entre 1985 y 2019 (Gobierno de Colombia, 2019).
} 
estudiado fue zona de enfrentamiento entre los diversos grupos armados, siendo parte de los municipios de la zona de distensión. ${ }^{8}$

Para la elaboración de los relatos de vida se realizaron encuentros donde se generó el diálogo para las entrevistas narrativas con los colaboradores, espacio en los cuales se guió la conversación en torno a la experiencia de juventud vivenciada en estos contextos de guerra. Los relatos de vida (Pujadas, 200o) construidos fueron analizados a través del proceso de análisis de contenido (Ruiz, 2006), donde se identificaron las tramas narrativas desde las que se definieron tópicos generales a analizar, inspirados en los marcadores de la juventud propuestos por Elder (1985); particularmente: el contexto de la guerra, los acontecimientos significativos desde la infancia y las transiciones y agencias juveniles.

\section{Resultados}

\section{La Merced: de los escenarios del juego a los del miedo}

\section{Contexto de la guerra paramilitar ${ }^{9}$}

En relación a las particularidades del territorio, Jorge recuerda cómo fue el cambio cuando llegaron los grupos paramilitares:

Todas estas zonas (occidente de Caldas) han sido conquistadas o por los paramilitares o por la guerrilla (...). Un personaje muy reconocido acá dentro de la arriería desapareció, (...) a partir de ese momento llegan los paramilitares a La Merced, y poco a poco conquistan casas, calles y parques hasta que se vuelve municipio no de nosotros sino de ellos...; donde usted salía a la calle y eran camionetas llenas de ejército (...); los policías se escondían cuando llegaban los paras al parque. (Comunicación personal)

Las experiencias de vida en dicho entorno de guerra están fuertemente marcadas por la violencia directa de estos grupos que generaban muerte, así como amedrentamiento en la población del territorio:

\footnotetext{
${ }^{8} \mathrm{La}$ «zona de distensión» entre los años de 1998 a 2002 acordada por el gobierno del presidente Andrés Pastrana con las Farc-EP (mediante Resolución 85 de 14 de octubre de 1998), para adelantar un proceso de paz con dicho grupo guerrillero. Terminó con el reinicio del conflicto.

${ }^{9}$ Los paramilitares son grupos cuyo objetivo es la lucha contrainsurgente, dirigiendo su violencia contra las bases sociales de las guerrillas, la izquierda política y los movimientos sociales, constituyéndose como estructuras de vigilancia y patrullaje armado legales, conformadas por la población civil (Zelik, 2015).
} 
A un tío de uno de los pelados fueron y se lo sacaron de allá de la propia casa y llegaron y lo mocharon con una motosierra en las pineras; lo partieron en pedacitos y que luego lo picaron y lo echaron en una bolsa, se lo llevaron a la casa y le dijeron que eso era por sapo. (Carlos, comunicación personal)

Por otra parte, la presencia paramilitar en La Merced generó modos de vida que no solo se relacionan con la violencia directa, sino también con la fiesta y con traer mujeres de otros lugares para las mismas. En aquellas los mercedeños observaban y en algunas oportunidades también participaban, pero no podían oponerse ni cuestionar porque ello significaba la muerte:

Sí mantenía en rumbas; aquí colocaban el equipo papi y se escuchaba hasta mi casa mijo, y los vecinos (...), con mujeres por todas partes; ellos traían las mejores niñas. Un montón de hembras hermosas ahí en ese balcón. (Carlos, comunicación personal)

\section{Acontecimientos significativos desde la infancia}

Los acontecimientos significativos referidos por Jorge se desarrollaron a la par de la violencia paramilitar, principalmente en su vinculación al colegio:

Pasé al colegio donde marqué una historia, marqué una historia dentro de los jóvenes. Empecé a desarrollar mi propia personalidad y al final fui un referente que, en diferentes ocasiones, de diferentes grupos sociales que se movían dentro de la institución (...). He sido como de todo un poquito, dentro de todo ese marco educativo del colegio me tocó vivir la época de la violencia. (Comunicación personal)

La presencia paramilitar trajo consigo cambios en los hábitos de la vida cotidiana de los jóvenes del territorio, dejando de estar en la calle por temor:

Los barrios se cambiaron, de escenarios de juego, por escenarios de miedo, muchas veces porque ya no podíamos jugar libremente (...). Muchas veces teníamos que salir corriendo porque pasaban los camiones cargados de personas. Sujetos armados hasta los dientes; entonces nosotros eso era nuevo para nosotros y para la casa de una por el temor (Jorge, comunicación personal)

Tanto Jorge como Carlos dan cuenta del modo en que siendo jóvenes vivenciaron la censura por parte del control paramilitar que intervenía en prácticas cotidianas desde la punición, prohibiendo la toma de fotografías en el espacio público de personas conocidas de ellos o a ellos directamente: 
Estábamos en un paseíto en una finca de acá del municipio donde hay una piscina y los del salón nos fuimos ahí para la piscina. No nos habían dicho que había una reunión de los medios mandos de ese grupo. Cuando nosotros estábamos tirando piscina, yo tenía una camarita y era tomando fotos y se me acercó uno de ellos y me dice: «ojo con esas fotos...». Casi..., casi tiro esa cámara allá pues para que se acabe de dañar y el temor fue muy grande. (Jorge, comunicación personal)

También hubo prácticas juveniles que fueron perseguidas. Los paramilitares persiguieron a quienes consideraban viciosos, principalmente por fumar o portar marihuana; esto último afectó a muchos jóvenes del territorio que fueron amedrentados violentamente y algunos de ellos asesinados, en el marco de la limpieza social como forma de regulación:

Antes de que ellos llegaran, este pueblo, mucho vicio, mucho marihuanero por esos potreros y todo eso. Cuando ellos empezaron a matar y todo eso porque los marihuaneros no se la creían. Ellos empezaron advirtiendo «no queremos a nadie fumando droga por ahí»; ellos no, esos manes hablan mucha mierda. Cuando empezaron a matar ahí sí, ya fueron cogiendo como miedo y a lo último esos potreros mantenían era solos, entonces ¿ellos qué hicieron? ellos ya empezaban pero a matar gente sapa, chismosa, a los rateros, los cogían y picaban. (Carlos, comunicación personal)

\section{Transiciones y agencias juveniles}

En los tiempos del paramilitarismo en el municipio se incorporó una nueva práctica social en los jóvenes: enrolarse en los grupos paramilitares como una posibilidad de ingresos de recursos económicos para ellos y sus familias, que vivían en condiciones de pobreza y en algunos casos desescolarizados. Dicha situación volvía atractivo un futuro vinculado al paramilitarismo:

Ellos [los paramilitares] fácilmente llegaban a un grupo de jóvenes, especialmente los de la zona rural y los conquistaban. ¿Cómo los conquistaban? «Venga es que usted va a poder ayudar a su familia» (...). Ahí cayeron primos míos, familiares, amigos, pelados que no estaban siendo educados y que trabajaban para sostener a las familias entonces se metían. (Jorge, comunicación personal)

Inicialmente, también resultó atractivo para los jóvenes pertenecer a las filas paramilitares por el significado vinculado a un estatus social de persona con poder sobre otros, sobre las mujeres, que llevan armas y que se divierten en grandes fiestas: «Nosotros pensábamos que meternos con los paracos era ir y estar con arma, que la gente nos 
viera que fuéramos grandes; pero ellos nunca creyeron que era para matar» (Carlos, comunicación personal).

Sin embargo, muchos jóvenes se enrolaron desde estas expectativas sin saber lo que implicaba ser parte del paramilitarismo. Ello conllevó a una ruptura con el modo de vida juvenil que llevaban al iniciar una existencia de la que no podían salir y eran obligados a aprender a matar, a volverse cómplices de muertes llevadas a cabo por el grupo; eran amenazados de muerte si develaban estos hechos:

Ellos se metían y ya no se podían salir; el que se quisiera salir lo iban era matando, porque haga de cuenta: yo me meto y yo después de matar y tener muchos secretos de esa gente. ¿Ustedes creen que a mí me van a dejar salir, así como así? ¡No! (Carlos, comunicación personal)

De este modo, tanto para Jorge como para Carlos implicarse en el paramilitarismo conllevaba una ruptura con los vínculos familiares, donde a los jóvenes se les obligaba a pasar como prueba el atentar contra la vida de un familiar. Esta situación marcaba una transición que afectó la relación con los más cercanos, rompiendo los lazos de los jóvenes con sus familias. La esperanza fijada inicialmente de pertenecer al grupo para poder apoyar a su familia se ve quebrantada, tal como también el hecho de dejar que la familia lo cuidara. También se rompía la confianza entre el grupo de pares, en tanto que se alimentaba la desconfianza entre los mismos compañeros de milicia:

Ellos no tenían corazón, que a más de uno le tocó probar finura matando un familiar. El que me contó eso le tocó matar a un tío, y lo más doloroso de eso es que cuando el duro de los paracos veía que no estaban dando rendimiento, ahí mismo los mandaban a matar a los mismos compañeros; o sea, entre ellos mismos se empezaban a matar y eso era algo hasta raro. (Carlos, comunicación personal)

El ingreso al paramilitarismo era bajo otras reglas. En algunos casos habían más de una persona de la familia que era paramilitar y desde ahí se establecían algunas dinámicas de protección. Pero aun así la familia ya no estaba para proteger al joven, ni la posibilidad para decidir continuar o retirarse. Salirse implicaba marcharse del pueblo:

Yo tuve un primo que nos contaba (...) que una vez lo pusieron a hacer un hueco y ese hueco era para un muerto; lo iban a matar a él, entonces se comunicó con uno de los medios mandos, pues un familiar, porque si lo encontraban lo mataban. Se fue y después regresó, 
pero con una infinidad de problemas. Él mismo terminó por suicidarse. (Carlos, comunicación personal)

Otro recuerdo que emerge en los relatos es el modo en que se imponían formas de dominación hacia las mujeres jóvenes, situación que permite ver el modo en que los paramilitares ejercían violencia sexual; sin embargo, luego formalizaban relaciones con sus víctimas públicamente, lo que se percibe por los colaboradores como prácticas que se legitimaban como un modo de tránsito a la adultez de las mujeres, como una práctica habitual socialmente aceptada:

Ellos, si se enamoraban de una pelada, tenían que coronarse a esa pelada o no quedaban contentos o a veces las cogían a la fuerza. Yo tuve una amiga que me contó que sí la cogió a la fuerza un man de esos, ipero como que le gustó! (...); para lo último terminó fue con él. (Carlos, comunicación personal)

Los relatos refieren que también había jóvenes que se resistían a las formas de vida atravesadas por el miedo que imponía el paramilitarismo y realizaban otro tipo de actividades culturales y de encuentro, que no eran permitidas, por lo que fueron amenazados y perseguidos. Muchos de estos jóvenes se tuvieron que ir del lugar para cuidar su vida, mientras otros se quedaron asumiendo que su posición ante la vida no era aceptada en el contexto de la guerra, por lo que lo identifican como una práctica de resistencia. Como lo plantea Jorge:

Me sucedió; éramos un grupo de amigos referentes dentro del conocimiento o las cosas diferentes que se hacían en el municipio. Era un amigo que estudiaba en la Javeriana en Bogotá, era otro que estaba estudiando en Manizales francés para irse para Canadá. Éramos como cinco, nos reuníamos, armábamos tertulias, caminábamos por todos los sitios acá del municipio y una vez uno de esos sujetos paramilitares nos hizo un disparo; nosotros íbamos caminado, llegaron de la camioneta y pun (...) que si nos volvían a ver nos iban a matar. A ellos les tocó irse del pueblo; yo no me fui porque yo quería resistir y todavía estoy resistiendo. (Comunicación personal)

Acerca del decidir quedarse en el territorio, Jorge refiere el hecho de haber tenido la oportunidad de trabajar por la transformación del territorio desde la creación de diferentes espacios culturales y deportivos con jóvenes; de tal manera, asumiendo una responsabilidad social por la transformación de lo que ha sido el ser joven en La Merced, lo cual describe como parte de su resistencia. 
No me quiero ir de mi municipio...; desde que tenga esa oportunidad de estar acá transformando a los pelados que tengo a cargo, eh..., comenzando una idea nueva de lo que es joven y de lo que es niño, de lo que es ser niño pues voy a estar acá. (Jorge, comunicación personal)

\section{Vista Hermosa (Meta): «Nos robaron el campo» Contextos de guerra entre actores armados (Farc-EP, paramilitares $y$ ejército)}

El contexto narrado por Hernán estuvo enmarcado por la presencia del ejército como actor armado que generó múltiples violencias:

Ha habido matanzas y masacres del Estado contra el pueblo, el pueblo contra el pueblo, de las organizaciones que se forman gracias a las políticas de Estado y se vienen contra el mismo pueblo bien sea de izquierda o derecha. (Comunicación personal)

Del mismo modo, previo a declararse la zona de distensión, el ejército impartía miedo, violencia y muerte, como un agente del que se debía huir:

Ellos entraban como ejército (...), pero actuaban como terroristas. Porque lo que le estoy diciendo es una realidad que se vivió en el año 1980 hasta el 1997, hasta cuando esto se convierte en zona de distensión (...); teníamos que huir, escuchábamos a una hora de camino: «Llegó el ejército, vuélese de esa finca porque llegaban o mataban»; violaban mujeres, ¡el ejército! (Hernán, comunicación personal)

La situación de violencia en el municipio también fue generada por la guerrilla, al buscar el modo de enrolar a los jóvenes: «del go para acá ya empezó la guerrilla a mirar los jóvenes con esa necesidad de involucrarlos en la guerra» (Hernán, comunicación personal).

En los periodos de mayor confrontación armada los jóvenes se veían amenazados, por una parte, cuando eran llevados por la guerrilla, como también cuando eran muertos por parte del ejército por apoyarla:

Entre los amigos uno decía: « $U_{y}$ no, vea que están llevando los muchachos para la guerrilla! Y el ejército en tal parte cogió unos muchachos y los mató, que porque eran guerrilleros, que eran raspachos, entonces hay que estar pilas». (Hernán, comunicación personal) 
En la memoria narrativa de Hernán, cuando el municipio hizo parte de la zona de distensión, fue un lugar intranquilo por la presión de las Farc-EP a distancia y de los milicianos ${ }^{10}$ en el casco urbano:

Cuando empieza el proceso de zona de distensión (...) la milicia era la que estaba pendiente de Vista Hermosa aquí en el casco urbano y la Farc pues en su montaña expandiendo su capital humano, su futuro y sus planes macabros para tomarse el poder (...); jlos de allá!, los grandes, estaban preparándose para tomar el poder de una forma sangrienta y lúgubre y los milicianos estaban aquí haciendo de la suyas abusando de ese poder. (Comunicación personal)

\section{Acontecimientos significativos desde la infancia}

Los relatos refieren una época donde el ejército los comienza a ver como enemigos, generando temor y violencias, vulnerando el derecho más básico a la vida, lo que los llevó a instaurar prácticas de protección y a que muchos jóvenes se enrolaran en la guerrilla:

El hecho más grande es vulnerar el derecho a la vida; era lo único que cuidamos, la vida. Se cuidaba a toda costa porque si nos dejamos atrapar del ejército nos mataban, encarcelaban, algo tenía que pasar. Pero era defender la vida porque muchas personas murieron a manos del ejército o los que no murieron y torturaron entonces después esos jóvenes se fueron para la guerrilla. (Hernán, comunicación personal)

En ese momento se vincula voluntariamente, ocultándoselo a su familia y a la Juventud Comunista Colombiana (Juco), de la que con el tiempo se desvincula por discrepancias, motivado principalmente por los estereotipos atribuidos a quienes pertenecían a ella:

Yo estuve en algo que mi papá no sabía, ni mi familia que se llamó la Juco (...); eso era más o menos entre los 13 y 15 años, y eso el que fuera de la Juco eso era ser un personaje importante; yo lo miraba desde ese punto de vista. (Hernán, comunicación personal)

El ser joven rural se deja ver en el relato de Hernán; un joven que trabajó en cultivos, luchando desde niño por la sobrevivencia, a la par de sus búsquedas ideológicas y su capacidad de soñar con futuros diferentes, como estudiar artes:

${ }^{10}$ Hace referencia a la denominación dada a las personas que apoyaban con información a la guerrilla de las Farc-EP, sin pertenecer a la fuerza armada de este grupo. 
Yo andaba de cultivo en cultivo (...). En esa época tenía que sobrevivir entre los 10 años de edad hasta los 20, cuando uno se hacía adulto. Ya uno era un niño adulto que pensaba, que sabía qué era bueno, qué era malo, qué tenía que conseguirse la comida, tenía que trabajar. Yo soñaba en un futuro, soñaba con salir a estudiar una de las cosas, qué le digo, literatura, pintura o artes plásticas o arquitectura. (Comunicación personal)

Hernán reconoce que el contexto de dicha época dejó traumas, donde el silencio fue una práctica de cuidado para el mantenimiento de la vida:

Las cosas negativas eran las que más dejaron huellas (...). Una vez que llevaron un muchacho lo subieron por el río arriba y fuimos a ver qué había pasado con él y lo habían dego1lado, le habían rasgado el estómago y lo habían botado al charco. Y eso me marcó, porque yo nunca había visto eso. ¡Cuando yo venía que el muchacho tal está...! ¡Cállese la boca y usted no ha visto nada! (...) Porque, si vamos a ver la historia en esos procesos, siempre ha habido personajes malos que hacen eso. (Comunicación personal)

Las formas de comunicación y estrategias para velar por el cuidado de los jóvenes, en los diferentes escenarios de la vida cotidiana, fueron controladas por las Farc-EP, las cuales establecían prácticas de castigo en las que las familias muchas veces mediaban:

Cuando algo pasaba, que llega un muchacho a cometer un error, rapidito mandaban alguien, «Mire dígale a fulano que le cogieron el chino, vaya avísele». Y tú, pues rápido coger un caballito y pues fulano que le amarraron a su hijo porque pasó esto y esto. (Hernán, comunicación personal)

\section{Transiciones y agencias juveniles}

La narrativa de Hernán da cuenta del tiempo de mayor conflictividad armada entre guerrilla y ejército, lo que generó un cambio en los tránsitos juveniles, no permitiendo otros referentes que no estuviesen involucrados en el conflicto armado, como cuerpos guerreros o vinculados al cultivo y cosecha de la hoja de coca: «no había más alternativas para los jóvenes: vuélvase miliciano o guerrillero o raspacho o gánese problemas por ahí» (comunicación personal).

Los tránsitos que Hernán refiere fueron alimentados por el rencor ocasionado por las pérdidas que llevaban a romper el tejido social, pues se vivía en constante resentimiento hacia los otros, práctica de la que él atribuye se alimentó el paramilitarismo en la zona posterior al 2000, llegando a cambiar hábitos de la vida cotidiana en las familias, en la comunidad y, por ende, en la configuración del ser joven: 
Los padres o hermanos de personas afectadas por un grupo u otro decían: «iMijo cobremos venganza!» ¿Qué hay que hacer entonces?, métase a un grupo y todos vamos para allá a cobrar venganza en contra (...). Y casi todas las familias enteras se volvían paramilitares. (Comunicación personal)

Otro camino, en las épocas de mayor confrontación, fue el de los jóvenes como él, raspachines, que buscaban su sustento itinerante y clandestinamente, huyendo de los lugares de enfrentamiento armado:

Los jóvenes teníamos que escondernos. La juventud de nosotros fue un ir, venir, huya, trabaje en un lado; cuando se ponía pesado que había ejército, que a tal región no podíamos ir a coger la hoja de coca por allá, nos tocaba bajarnos por el lado de puerto Toledo, para el lado de la cooperativa, de puerto Gabriel, íbamos buscando otros sitios. (Comunicación personal)

Por otra parte, Hernán refiere que su vínculo a los cultivos de coca le proporcionó autonomía económica, a lo que atribuye una época en donde gastó muy fácil el dinero al tomar mucho alcohol. A raíz de ello con el tiempo deja de cultivar coca y se dedica a diversificar sus cultivos:

A los 17 años sembré mi primer cultivo de coca, como tres hectáreas, en socio con un muchacho, y ese sueño de conseguir plata para abrirme para el Amazonas; y llegaba a Piñalito y ahí gastaba todo el recurso y otra vez vuelva allá sin nada, sin cultivo y siga trabajando por la misma. Hasta que un día tomé la decisión (después de ser alcohólico) de dejar de coger hoja de coca. (Comunicación personal)

El cuidado se volvió una práctica social para la protección y la sobrevivencia que se desarrolló desde la familia, tanto para proteger del riesgo de que fueran enrolados en la guerrilla, como también de la desconfianza entre pares; esto ya que había otros jóvenes que participaban de los grupos y se presentaban como factor de riesgo para quien que no estuviera enrolado:

Ya muchos amigos se volvieron milicianos y ya empezaron a espulgarle a uno la lengua, a hablar mal, a ver uno qué decía para ir a contarles allá donde los mandos y hacerlo amarrar a uno. Entonces ya mi papá decía: «Pilas con estos muchachos, es mejor que los vaya apartando porque ellos están organizados y cualquier cosita usted como es de rebelde, dice cualquier cosa con ironía y me lo salen matando por ahí; pilas». (Comunicación personal) 
Sin embargo, Hernán narra el hecho de que su padre fue muerto por la guerrilla y evoca recuerdos de su vida en los que deja de soñar con sus proyecciones de futuro, vinculadas al campo, y con ello su desplazamiento lejos de la tierra que lo vio nacer:

Pues, primero, pierdo el sueño que es el campo, porque soy campesino cien por ciento; segundo, tengo que escaparme a un sitio donde no era lo mío, un ambiente muy diferente; y, tercero, me le quitó la vida a mi padre, esa guerra, que es gracias a las políticas de Estado fundamentadas por los que nos gobiernan, es que se han generado esas guerras. (Comunicación personal)

Finalmente, es en el espacio de la educación — de la mano de un maestro- lo que le permitió superar el rencor que le movió a la venganza de su padre. Es en este espacio donde Hernán encuentra el lugar para reflexionar y sensiblemente cambiar sus motivaciones - y las de otros jóvenes - hacia la guerra, acercándose a las artes como modo de proyectar otros futuros posibles; poder soñar, por ejemplo, con estudiar en la universidad o ser artista en el territorio:

El tema de motivarlos [a los jóvenes] a que pensaran diferente que la guerrilla no era una alternativa, los paramilitares no eran una alternativa; para cambiar, para vivir que se dedicaran a estudiar a hacer algo y por medio del dibujo y la pintura los iba motivando. (Comunicación personal)

\section{Discusión}

De los resultados obtenidos llama la atención las diferentes expresiones de la violencia en los territorios. En la Merced el dominio paramilitar y la convivencia con la violencia directa de guerra marcó la condición juvenil; mientras que en Vista Hermosa, la violencia directa no siempre estuvo vinculada al espacio cotidiano de la población civil, pero el control de las Farc-EP en el territorio propició otras prácticas de interacción (familiares, sociales y económicas). Situaciones que determinaron los cursos de vida para los jóvenes, por los roles que necesitó la guerra, confirmando lo planteado en los antecedentes (CNMH, 2018).

La investigación da cuenta que, tanto en La Merced como en Vista Hermosa, en tiempos de guerra se tendió a la homogenización de los cuerpos jóvenes; por una parte, desde el miedo y la barbarie y, por otra, a través de estrategias de administración de la vida por 
el poder soberano de los grupos armados, donde los y las jóvenes tenían que estar disponibles para la guerra y aprender a vivir en ella.

También se evidencia que, mientras más aguda la violencia de guerra, más se atentó contra los lazos sociales, alterándolos de modo que, en muchos casos, llegaron a ser funcionales al mantenimiento del conflicto, dejando de ser factor de protección y cuidado. Acerca de este tema el estudio de Carvajal y Galvis (2018), en relación a los efectos de la violencia paramilitar en Miraflores (Bojayá), confirma que de estos escenarios emergió un sufrimiento social como consecuencia de las heridas dejadas por la guerra. Ello favoreció el posicionamiento de la desconfianza entre los miembros de la comunidad en el diario vivir, lo que restó y sigue restando a los jóvenes de espacios comunitarios de protección y cuidado, marcando sus cursos de vida.

Sin embargo, los colaboradores reconocieron como prácticas de cuidado familiar emergente en tiempos de guerra al desplazamiento de los jóvenes de los territorios para protegerlos, así como el espacio de la escuela, legitimado como lugar de recreación, esparcimiento y creación en La Merced.

En cuanto a los tránsitos de vida posibles para las mujeres jóvenes en tiempos de guerra, se planteó un modo de transición a la vida adulta en La Merced, marcado por la violencia sexual paramilitar que se legitimó socialmente como práctica; posteriormente, hubo jóvenes que se establecían como pareja del agresor. Situación también planteada por el Centro Nacional de Memoria Histórica (2017) como una modalidad de violencia instaurada para dominar y ejercer poder en el cuerpo del otro (en este caso en la mujeres jóvenes). Este aspecto se constituye en un dispositivo de subjetivación relacionado con el ejercicio de crueldad, horror, temor y miedo que deseaban instaurar en los territorios para el ejercicio del poder y la dominación (Guerrero-Martelo et al., 2017, p. 82).

En el caso de los hombres, en los dos territorios se legitimó mayormente el tránsito al cuerpo guerrero de los jóvenes, como modo de salir de la pobreza o por estereotipos de virilidad y venganza (tanto en el caso del paramilitarismo o para las Farc-EP), al que se suma el tránsito marcado por convicciones políticas. De lo anterior, el enrolamiento por precariedad resulta acorde a lo planteado en las narrativas de los exparamilitares acogidos a Justicia y Paz, mencionados en los antecedentes (CNMH, 2018, pp. 167-177), ,1

\footnotetext{
${ }^{11}$ Opción de vinculación ocupacional que se relaciona con la situación de pobreza en las zonas rurales y, peor aún, la incidencia de la pobreza en el número de jóvenes en esta misma zona; ejemplo de ello, para el 2005 la incidencia de pobreza para jóvenes rurales fue 1.3 veces mayor a la de jóvenes urbanos y la brecha se está ampliando cada vez más (Pardo, 2017).
} 
así como en el hecho de la decisión de ser parte de las Farc-EP vinculado a convicciones políticas que plantea Beltrán (2015).

En ambos territorios se da cuenta que, cuando los jóvenes decidían ser parte de los grupos armados, las familias perdían incidencia en su curso de vida, y con mayor agudeza cuando se vinculaban a un grupo paramilitares. El enrolamiento en el paramilitarismo significó para los jóvenes un cambio de las reglas morales que configuran formas de cuidado social, imposibilitando la renuncia a este camino y determinando la pérdida de agencia juvenil gestada desde el ensayo error con los pares, desde el adoctrinamiento y el miedo. Desde este último se preparó a jóvenes de ambos territorios para matar hasta a su propia comunidad, tránsito que generó trauma psicosocial en jóvenes de la Merced arrebatándoles su juventud.

Los hallazgos coinciden con las narrativas en el proceso de justicia y paz al referir que el reclutamiento fue un engaño, dado que sabían que iban a pertenecer al grupo, pero desconocían su rol específico, las condiciones de salario, la destinación de su tiempo y las restricciones a las que iban a estar sometidos (CNMH, 2018).

Otro tránsito descrito fue el participar del cultivo de la hoja de coca y su cosecha como raspachines, lo que se ha venido trazando desde las disputas de la guerra, particularmente para los jóvenes rurales, diferentes a las formas tradicionales del campesinado ya planteado en estudios anteriores (CNMH, 2018). Este camino prevalece en territorios como Vista Hermosa, dada la presencia aún de cultivos ilícitos.

Pese a lo anterior, cabe destacar que en ambos territorios los colaboradores de la investigación decidieron trazar otros tránsitos al margen de los delimitados por la guerra; estos fueron definidos por la decisión de desarrollar actividades colectivas (especialmente artísticas) con otros jóvenes. Prácticas que identifican como de resistencia al orden establecido por la guerra a los cursos de vidas juveniles, buscando otros modos de habitar sus territorios y reconstruir las relaciones comunitarias quebrantadas por el conflicto (Carvajal \& Galvis 2018). Agencias disidentes, en resistencia ante territorios en disputa, que dan cuenta que hubo jóvenes que perseveraron en sus caminos diversos pese a que el contexto tendió a desplazarlos, enrolarlos o desaparecerlos.

De este modo, y en concordancia con lo planteado por Amador-Baquiro (2016), los colaboradores dan cuenta en sus relatos de cómo han establecido formas de apoyo y solidaridad con otros jóvenes hasta el presente; acciones colectivas que les posibilitaron reinscribir su singularidad biográfica de la temporalidad de la muerte, desmarcándose de la 
condena que fijaron los marcos de guerra en sus transiciones, transformando el dolor y miedo en potencial de cambio en sus territorios. Así, superaron la marca del curso de vida por la tragedia del orden traumático de la guerra con sus efectos patologizantes (Parra-Valencia et al., 2018), transformándola en oportunidades de futuro para los actuales jóvenes en sus territorios.

Por otra parte, la elaboración de los relatos permitió la reconstrucción de memorias sociales. Este ejercicio se constituyó en sí mismo en una práctica de cuidado, de reconocimiento del otro, desde la posibilidad de poder contar aquello por mucho tiempo silenciado en la comunicación, a fin de compartir y ser escuchado (Jelin, 2002).

El ejercicio posibilitó levantar consciencia desde la esfera privada a la pública de lo ocurrido en La Merced y Vista Hermosa, abriéndonos a una reinterpretación desde el presente y posibilitando develar las experiencias de guerra vividas especialmente por los jóvenes (Prada-Sanmiguel, 2016). Dicha práctica tuvo limitaciones éticas y políticas que afectaron tanto a los colaboradores como a los investigadores, manteniendo un especial cuidado por lo emergente del espacio de la escucha desde la confidencialidad. Como investigación comprometida, buscó romper el silencio en espacios donde el miedo no emerge solo de una situación pasada, sino que el trauma parece reeditarse cotidianamente en condiciones del presente. En este la justicia no parece llegar a todos por igual, los castigos se muestran desproporcionados o inexistentes y en los territorios aún habitan personas que han sido parte de los grupos armados. Estas situaciones limitan los alcances sociales de lo emergente y agudizan las prácticas de cuidado de la vida de quienes se ven implicados en estos procesos, con un valor agregado de recoger lo que resulta significativo para los cursos de vida actuales de los jóvenes en la ruralidad, pero transita como parte de memorias subterráneas del tejido social (Pollak, 1989).

Finalmente, este ejercicio abre nuevas posibilidades de investigación, fundamentalmente por lo que develan los relatos. Es necesario profundizar en la comprensión de las configuraciones juveniles de las mujeres en la guerra. Por otra parte, el número de colaboradores permite dimensionar ciertos marcadores; sin embargo, es necesario seguir indagando en los diversos territorios de Colombia acerca del modo en que la guerra condicionó los cursos de vida de los jóvenes por décadas y de forma diferenciada en sus contextos rurales.

Esta investigación indica que es necesario seguir profundizando acerca de las particularidades de los acontecimientos vivenciados y de las subjetividades de los jóvenes que lograron reinterpretar su pasado y, con ello, reconfigurar los cursos de vida marcados por 
la guerra, desarrollando potenciales para el quehacer comunitario que aportan a la transformación de sus territorios desde acciones con otros jóvenes (especialmente artísticas). Estas prácticas de resistencia se vuelven de supervivencia de otros cursos de vida en contextos de guerra, y conllevan volver a habitar el mundo y reconstruir las relaciones comunitarias quebrantadas en el conflicto (Carvajal \& Galvis 2018).

\section{Agradecimientos}

Agradecemos a los y las jóvenes colaboradores de la Merced y Vista Hermosa, así como a la Universidad de Manizales por hacer posible este proyecto.

\section{Referencias}

Alba, G. (1997). La generación incógnita: un decálogo sobre los jóvenes colombianos de los 9o. Revista Universitas Humanística, 46(46).

Amador-Baquiro, J. C. (2016). Jóvenes, temporalidades y narrativas visuales en el conflicto armado colombiano. Revista Latinoamericana de Ciencias Sociales, Niñez y Juventud, $14(2), 1313-1329$.

Andrades, M., \& Benavides, A. (2012). Violencia política: recuperando y tejiendo la memoria entre dos generaciones a través de relatos de vida e imágenes [Tesis de Doctorado]. Universitat Autònoma de Barcelona.

Atkinson, R., \& Flint, J. (2001). Accessing hidden and hard-to-reach populations: snowball research strategies. Social Research Update. https://sru.soc.surrey.ac.uk/SRU33.html

Bedoya, J. G., García, S., Rodríguez, C., Sánchez, L. M., \& Sánchez, F. J. (2019). Trayectorias de desarrollo de los jóvenes en zonas de posconflicto: diagnóstico y propuestas de política. Universidad de los Andes.

Beltrán, M. (2015). La Farc-EP (1950-2015): luchas de ira y esperanza. Desde Abajo.

Berger, P., \& Luckmann, T. (1998). La construcción social de la realidad. Amorrortu.

Beristain, C. M., Pérez-Esquivel, A., \& Riera, F. (1993). Afirmación y resistencia: «la comunidad como apoyo». Virus.

Bourdieu, P. (1990). La juventud no es más que una palabra. Sociología y Cultura.

Calderón, P. (2009). Teoría del conflicto de Johan Galtung. Revista Paz y Conflicto, (2), 6o-81. 
Carvajal, P. M., \& Galvis, M. (2018). Violencia paramilitar en Miraflores: un pasado que se filtra en el presente. Centro de Investigación y Educación Popular.

Castellanos-Obregón, J. M. (2011). La condición juvenil: opciones metodológicas para la construcción de un objeto de conocimiento. Siglo del Hombre Editores; Universidad de Manizales; Cinde.

Castellanos-Obregón, \& Torres-Silva, W. F. (2008). Una revisión de la producción académica sobre la violencia política en Colombia para indagar sobre el lugar de los jóvenes y las jóvenes. Revista Latinoamericana de Ciencias Sociales, Niñez y Juventud, 6(2), 523-563.

Centro Nacional de Memoria Histórica. (2013). iBasta Ya! Colombia: memorias de guerra y dignidad. Centro Nacional de Memoria Histórica.

Centro Nacional de Memoria Histórica. (2017). La guerra inscrita en el cuerpo: informe nacional de violencia sexual en el conflicto armado. Centro Nacional de Memoria Histórica.

Centro Nacional de Memoria Histórica. (2018). Violencia paramilitar en la altillanura. Centro Nacional de Memoria Histórica.

Elder, G. H. (1985). Life course dynamics: Trajectories and transitions, 1968-1980. Cornell University Press.

Feixa, C. (1999). De Jóvenes, bandas y tribus: antropología de la juventud. Ariel.

Galtung, J. (2004). Violencia, guerra y su impacto: sobre los efectos visibles e invisibles de la violencia. http://www.lopezaso.com/adm/contenido/48.pdf

Gergen, K., \& Gergen, M. (2011). Reflexiones sobre la construcción social. Paidós.

Gobierno de Colombia. (2019). Registro único de víctimas (RUV). https://bit.ly/3q2dRaw

González-Cangas, Y. (2003). Juventud rural: trayectorias teóricas y dilemas identitarios. Nueva Antropología, $19(63), 153-175$.

Guerrero-Martelo, M., Granados-García, A., \& Galván, G. (2017). Configuración de subjetividades relacionadas con el comportamiento cruel en grupos paramilitares en Colombia: un aporte a la preparación para un eventual período de postconflicto. En J. J. Hernández, A. Ramírez, \& J. L. Barboza (Comps.), Conflictos y posconflictos: pasado y presente en América Latina y el Caribe, caso Colombia (pp.81-107). Corporación Universitaria del Caribe.

Halbwachs, M. (2005). Memoria individual y memoria colectiva. Estudios, (16), 163-187.

Jelin, E. (1994). Las familias en América Latina: familias siglo XXI. Ediciones de las Mujeres 20. Jelin, E. (2002). Los trabajos de la memoria. Siglo XXI.

Jurado, C., \& Tobasura, I. (2012). Dilema de la juventud en territorios rurales de Colombia: ¿campo o ciudad? Revista Latinoamericana de Ciencias Sociales, Niñez y Juventud, 1o(1), 63-77. 
Kessler, G. (2005). Estado del arte de la investigación sobre juventud rural en América Latina. Unesco, Instituto Internacional de Planeamiento de la Educación.

Koessl. M. (2015). Violencia y habitus: paramilitarismo en Colombia. Siglo del Hombre.

Mantilla-Flórez, S. M., Moreno-Gómez, D. L., \& Naraváez-López, L. P. (2018). Trayectoria de vida construida por joven expuesta al conflicto armado en el departamento del Putumayo [Tesis de maestría]. Universidad de Manizales-Cinde.

Margulis, M. (2001). Juventud: una aproximación conceptual. Alianza.

Margulis, M., \& Urresti, M. (1998). La construcción social de la condición de juventud. Paidós.

Martín-Barbero, J. (1998). Jóvenes: des-orden cultural y palimpsestos de identidad. Universidad Central; Siglo del Hombre.

Martín-Baró, I. (1990). Guerra y trauma psicosocial del niño salvadoreño. UCA Editores.

Montero, M. (2004). Introducción a la psicología comunitaria: desarrollo, conceptos y procesos. Paidós.

Mosqueira, M. A. (2010). «De menores y consumidores». Construcción socio-histórica de la(s) juventud(es) en la Argentina. Revista Latinoamericana de Ciencias Sociales, Niñez y Juventud, 8(1), 105-129.

Muñoz-López, S. M., \& Alvarado, S. V. (2011). Autonomía en movimiento: una reflexión desde las prácticas políticas alternativas de jóvenes en Colombia. Revista Latinoamericana de Ciencias Sociales, Niñez y Juventud, 9(1), 115-128.

Ospina-Ramírez, D. A., \& Ospina-Alvarado, M. C. (2017). Futuros posibles: el potencial creativo de niñas y niños para la construcción de paz. Revista Latinoamericana de Ciencias Sociales, Ninez y Juventud, 15(1), 175-192.

Pardo, R. (2017). Diagnóstico de la juventud rural en Colombia. Grupos de diálogo rural: una estrategia de incidencia. Centro Latinoamericano de Desarrollo Rural.

Parra-Valencia, L., Aponte-Muñoz, A. C., \& Dueñas-Manrique, M. M. (2018). Jóvenes, grupo y arte: las personas jóvenes y el arte re-unidos. Revista Latinoamericana de Ciencias Sociales, Niñez y Juventud, 16(2), 853-865. https://doi.org/fnxs

Pineda, J., \& Muñoz, G. (2017). Robándole tiempo a la muerte. Colciencias; Universidad de Manizales; Universidad Pedagógica Nacional; Cinde.

Pollak, M. (1989). Memória, esquecimento, silêncio. Revista Estudos Históricos, 2(3), 3-15.

Prada-Sanmiguel, A. (2016). Comprensión de la responsabilidad política de los actores armados en el conflicto interno colombiano: la masacre de El Salado 20oo. Revista Latinoamericana de Ciencias Sociales, Niñez y Juventud, 14(2), 1537-1548.

Puig, G., \& Rubio, J. L. (2015). Tutores de resiliencia: dame un punto de apoyo y moveré mi mundo. Gedisa. 
Pujadas, J. J. (2000). El método biográfico y los géneros de la memoria. Revista de Antropología Social, (9), 127-158.

Reguillo, R. (2010). La condición juvenil en el México contemporáneo: biografías, incertidumbres y lugares. En R. Reguillo (ed.), Los jóvenes en México (pp. 395-429). Fondo de Cultura Económica; Conaculta.

Reguillo, R. (2017). Paisajes insurrectos. Nuevos Emprendimientos.

Rodríguez, O. (2017). Los sentires del fútbol como prácticas de resistencia en la juventud de La Merced [Tesis de Maestría]. Cinde-Universidad de Manizales, Manizales, Colombia.

Rovira-Rubio, R. (2014). La pobreza en Chile y su superación como problema del Estado [Tesis Doctoral]. Universidad Autónoma de Barcelona.

Rovira-Rubio, R., Valencia-Salazar, L. V., Quirós-Tamayo, J. A., Orozco-Montoya, L. A., Amelines-Guerrero, D. C., \& Alberto, Y. (2018). La investigación como herramienta para la resistencia, tres experiencias desde la construcción del reconocimiento, la memoria y la comunidad. Universidad Pedagógica Nacional; Cinde; Universidad de Manizales.

Ruiz, A. (2006). Texto, testimonio y metatexto: el análisis de contenido en la investigación en educación. En A. Torres, \& C. Jiménez (Comps.), La práctica investigativa en Ciencias Sociales (pp. 43-61). Universidad Pedagógica Nacional.

Sepúlveda, L. (2013). Juventud como transición: elementos conceptuales y perspectivas de investigación en el tiempo actual. Última Década, 21(39), 11-39. https://doi.org/ 10.4067/s0718-22362013000200002

Simmonds, T. \& Hurtado, D. (2011). Imaginarios de juventud y ciudad en maestras y maestros de la ciudad de Popayán. En G. Muñoz (Ed.), Jóvenes, culturas y poderes. (pp. 125-144). Siglo del Hombre Editores; Universidad de Manizales; Cinde.

Tobón, F. Q. (2005). De jóvenes y juventud. Revista Nómadas, (23), 94-103.

Valenzuela, J. M. (coord.) (2015). Juvenicidio, Ayotzinapa y las vidas precarias en América Latina y España. NED.

Zelik, R. (2015). Paramilitarismo. Violencia y transformacion social, política y económica en Colombia. Siglo del Hombre; Fescol; Goethe Institut. 